\title{
A case of gallbladder neuroendocrine carcinoma diagnosed preoperatively using somatostatin receptor scintigraphy
}

\author{
YUSUKE KAMIKIHARA $^{1}$, SHIROH TANOUE ${ }^{1}$, MACHIKO KAWAHIRA ${ }^{1}$, HIROMICHI IWAYA ${ }^{1}$, \\ SHIHO ARIMA $^{1}$, FUMISATO SASAKI ${ }^{1}$, YUICHIRO NASU ${ }^{1}$, SHINICHI HASHIMOTO ${ }^{1}$, \\ SHUJI KANMURA ${ }^{1}$, MICHIYO HIGASHI ${ }^{2}$, KENTARO GEJIMA $^{3}$ and AKIO IDO ${ }^{1}$ \\ ${ }^{1}$ Digestive and Lifestyle Diseases, Kagoshima University Graduate School of Medical and Dental Sciences; \\ ${ }^{2}$ Department of Pathology, Kagoshima University Hospital; ${ }^{3}$ Cardiovascular and Gastroenterological Surgery, \\ Graduate School of Medical and Dental Sciences, Kagoshima University, Kagoshima 890-8544, Japan
}

Received May 20, 2019; Accepted October 8, 2019

DOI: $10.3892 / \mathrm{ol} .2019 .11101$

\begin{abstract}
Gallbladder neuroendocrine carcinoma (NEC) is a rare gallbladder tumor. The current report is a case of a patient preoperatively diagnosed with gallbladder NEC using somatostatin receptor scintigraphy (SRS). A 63-year-old man was admitted to our hospital by a family doctor after abdominal ultrasonography revealed thickened walls of the neck of his gallbladder. At Kagoshima University Hospital, CT and MRI of the abdomen and endoscopic ultrasonography confirmed the thickening of the walls of the neck of the gallbladder. However, it did not resemble a typical gallbladder cancer or tumor, such as a neuroendocrine tumor or malignant lymphoma. Positron emission tomography and SRS showed abnormal accumulation at the tumor site. Endoscopic retrograde cholangiopancreatography was performed, adenocarcinoma was suspected based on intra-gallbladder bile cytology, and a cholecystectomy with lymphadenectomy was performed. The postoperative pathological diagnosis was small cell NEC (pT3a, N0, M0, stage II). Immunohistochemistry indicated that the gallbladder tumor cells were positive for synaptophysin, chromogranin A, and cluster of differentiation (CD) 56, and negative for somatostatin receptors (SSTR) 2 and 5. Gene expression assays revealed the expression of all SSTR subtypes (SSTR1-5) in the tumor. Generally, NECs exhibit poor accumulation in SRS, however, the results of the current case suggest that SRS may be useful in the preoperative diagnosis of NEC.
\end{abstract}

Correspondence to: Dr Shiroh Tanoue, Digestive and Lifestyle Diseases, Kagoshima University Graduate School of Medical and Dental Sciences, 8-35-1 Sakuragaoka, Kagoshima-shi, Kagoshima 890-8544, Japan

E-mail: tanoue@m.kufm.kagoshima-u.ac.jp

Key words: gallbladder neuroendocrine carcinoma, somatostatin receptor scintigraphy

\section{Introduction}

Neuroendocrine tumors (NETs), which account for $<1 \%$ of all malignant tumors, originate from disseminated neuroendocrine cells. Most NETs are found in the gastrointestinal and respiratory tracts (1). Neuroendocrine carcinomas (NECs) in the gastrointestinal tract are mostly found in the rectum, jejuno-ileum, and pancreas. Primary NEC of the gallbladder is a rare disease, it makes up $1.4 \%$ of all gastrointestinal endocrine tumors, and $0.4-4 \%$ of all malignant tumors that occur in the gallbladder (2). In general, somatostatin receptor scintigraphy (SRS) has a low diagnostic sensitivity for NECs and ${ }^{18} \mathrm{~F}$ fluorodeoxyglucose (FDG)-positron emission tomography (PET) is useful in the diagnosis of tumors with a high proliferation index and high glucose consumption.

Here, we report a case of a patient preoperatively diagnosed with gallbladder NEC using SRS.

\section{Case presentation}

A 63-year-old man with no complaints visited a doctor for abdominal ultrasonography (AUS) screening. AUS revealed thickening of the gallbladder wall. The patient was therefore admitted to our hospital for further examination. He was taking medication for hypertension and type 2 diabetes and he had a family history of lung cancer.

Blood analysis at the time of admission revealed mild liver dysfunction. No elevation in the levels of tumor markers such as carcinoembryonic antigen (CEA), cancer antigen 19-9 (CA 19-9), neurospecific enolase (NSE), or pro-gastrin-releasing peptide was observed. There were no abnormalities in the levels of hormones such as insulin, glucagon, or gastrin (Table I-V). AUS showed a low-echoic mass $(22 \times 14 \mathrm{~mm})$ with clear boundaries to the liver, protruding into the lumen from the gallbladder neck (Fig. 1).

Abdominal contrast-enhanced computed tomography (CT) showed wall thickening that appeared to extend into the lumen of the gallbladder neck with a weak contrast effect. No obvious out-of-wall development was observed (Fig. 2).

In abdominal magnetic resonance imaging (MRI), the tumor showed a low signal intensity on T1 imaging and a high 
Table I. Hematology.

\begin{tabular}{|c|c|c|}
\hline Hematology & Result & Unit \\
\hline WBC & 3710 & $/ \mu 1$ \\
\hline Lymph & 25.3 & $\%$ \\
\hline Mono & 4.9 & $\%$ \\
\hline Eosino & 1.1 & $\%$ \\
\hline Baso & 0.3 & $\%$ \\
\hline Neut & 68.4 & $\%$ \\
\hline $\mathrm{RBC}$ & $543 \times 10^{4}$ & $/ \mu 1$ \\
\hline $\mathrm{Hb}$ & 14.6 & $\mathrm{~g} / \mathrm{dl}$ \\
\hline Hct & 44.2 & $\%$ \\
\hline Plt & $16.3 \times 10^{4}$ & $/ \mu 1$ \\
\hline \multicolumn{3}{|c|}{$\begin{array}{l}\text { WBC, White blood cells; Lymph, Lymphocytes; Mono, Monocytes; } \\
\text { Eosino, Eosinocytes; Baso, Basophils; Neutro, Neutrophils; RBC, } \\
\text { Red blood cells; Hb, Hemoglobin; Hct, Hematocrit; Plt, Platelets. }\end{array}$} \\
\hline \multicolumn{3}{|c|}{ Table II. Coagulation. } \\
\hline Coagulation & Result & Unit \\
\hline PT & 118 & $\%$ \\
\hline D-Dimer & $<0.5$ & $\mu \mathrm{g} / \mathrm{ml}$ \\
\hline FDP & 3.1 & $\mu \mathrm{g} / \mathrm{ml}$ \\
\hline
\end{tabular}

PT, Prothrombin time; FDP, Fibrin degradation products.

signal intensity on T2 imaging that was slightly higher than the liver parenchyma. An apparent high diffusion signal was observed in diffusion-weighted imaging (DWI) and the signal declined with apparent diffusion coefficient mapping. The mucosal surface was preserved. These findings were indicative of a NET and a malignant lymphoma with higher cell density than that of a typical gallbladder cancer. Magnetic resonance cholangiopancreatography showed a defect in the neck of the gallbladder (Fig. 3).

Endoscopic ultrasonography findings were similar to those of AUS and showed a structure of submucosal tumor-like appearance and clear boundaries to the liver. No Rokitansky-Aschoff sinus was observed. Endoscopic retrograde cholangiopancreatography showed a defect in the neck of the gallbladder and pancreaticobiliary malfunction was not observed. The amylase levels in the bile juice was not elevated. An endoscopic naso-gallbladder drainage catheter was placed in the gallbladder, and bile cytology, which was performed 4 times, revealed a large number of heterogeneous cell clusters. Adenocarcinoma was suspected based on these findings (Fig. 4).

Positron emission tomography/computed tomography (PET/CT) revealed the abnormal accumulation of ${ }^{18} \mathrm{~F}$ fluorodeoxyglucose (FDG) in the gallbladder wall (Maximum standard uptake value: $5.8 \rightarrow 8.8$ ), with no findings suggestive of distant organ metastasis.

SRS was performed because gallbladder NET was also considered as a possible diagnosis. Abnormal accumulation
Table III. Serum chemistry.

\begin{tabular}{lcc}
\hline Serum chemistry & Results & $\mathrm{Unit}$ \\
\hline AST & 35 & $\mathrm{IU} / \mathrm{l}$ \\
ALT & 46 & $\mathrm{IU} / \mathrm{l}$ \\
LDH & 192 & $\mathrm{IU} / \mathrm{l}$ \\
ALP & 122 & $\mathrm{IU} / \mathrm{l}$ \\
$\gamma$-GTP & 43 & $\mathrm{IU} / \mathrm{l}$ \\
T-Bil & 0.8 & $\mathrm{mg} / \mathrm{dl}$ \\
D-Bil & $<0.03$ & $\mathrm{mg} / \mathrm{dl}$ \\
TP & 7.3 & $\mathrm{~g} / \mathrm{dl}$ \\
ALB & 4.8 & $\mathrm{~g} / \mathrm{dl}$ \\
BUN & 14.5 & $\mathrm{mg} / \mathrm{dl}$ \\
Cre & 0.91 & $\mathrm{mg} / \mathrm{dl}$ \\
$\mathrm{Na}$ & 138 & $\mathrm{mEq} / \mathrm{l}$ \\
$\mathrm{K}$ & 4.5 & $\mathrm{mEq} / \mathrm{l}$ \\
$\mathrm{Cl}$ & 104 & $\mathrm{mEq} / \mathrm{l}$ \\
$\mathrm{Ca}$ & 9.5 & $\mathrm{mEq} / \mathrm{l}$ \\
$\mathrm{CRP}$ & 0.03 & $\mathrm{mg} / \mathrm{dl}$ \\
\hline
\end{tabular}

AST, Aspartate transaminase; ALT, Alanine aminotransferase; LDH, Lactate dehydrogenase; ALP, Alkaline phosphatase; $\gamma$-GTP, $\gamma$-Glutamyl transpeptidase; T-Bil, Total bilirubin; D-Bil, Direct bilirubin; TP, Total protein; ALB, Albumin; BUN, Blood urea nitrogen; Cre, Creatinine; CRP, C-reactive protein.

Table IV. Tumor markers.

\begin{tabular}{lrc}
\hline Tumor markers & Results & Unit \\
\hline CEA & 1.5 & $\mathrm{ng} / \mathrm{ml}$ \\
CA19-9 & 8.7 & $\mathrm{U} / \mathrm{ml}$ \\
NSE & 13.6 & $\mathrm{ng} / \mathrm{ml}$ \\
ProGRP & 27.6 & $\mathrm{pg} / \mathrm{ml}$ \\
\hline
\end{tabular}

CEA, Carcinoembryonic antigen; CA19-9, carbohydrate antigen; NSE, Neuron-specific enolase; ProGR, gastrin releasing peptide.

Table V. Hormones.

\begin{tabular}{lcc}
\hline Hormones & Result & Unit \\
\hline Insulin & 11.3 & $\mu \mathrm{U} / \mathrm{ml}$ \\
Glucagon & 174 & $\mathrm{pg} / \mathrm{ml}$ \\
Gastrin & 91 & $\mathrm{pg} / \mathrm{ml}$ \\
\hline
\end{tabular}

was apparent in SRS and is consistent with a tumor. No other abnormal accumulation suggestive of metastasis was observed (Fig. 5).

Gallbladder NEC was suspected based on the above findings. However, are suspected diagnosis was stage II gallbladder carcinoma based on the results of bile cytology. Therefore, we performed enlarged cholecystectomy and D2 lymphadenectomy. 

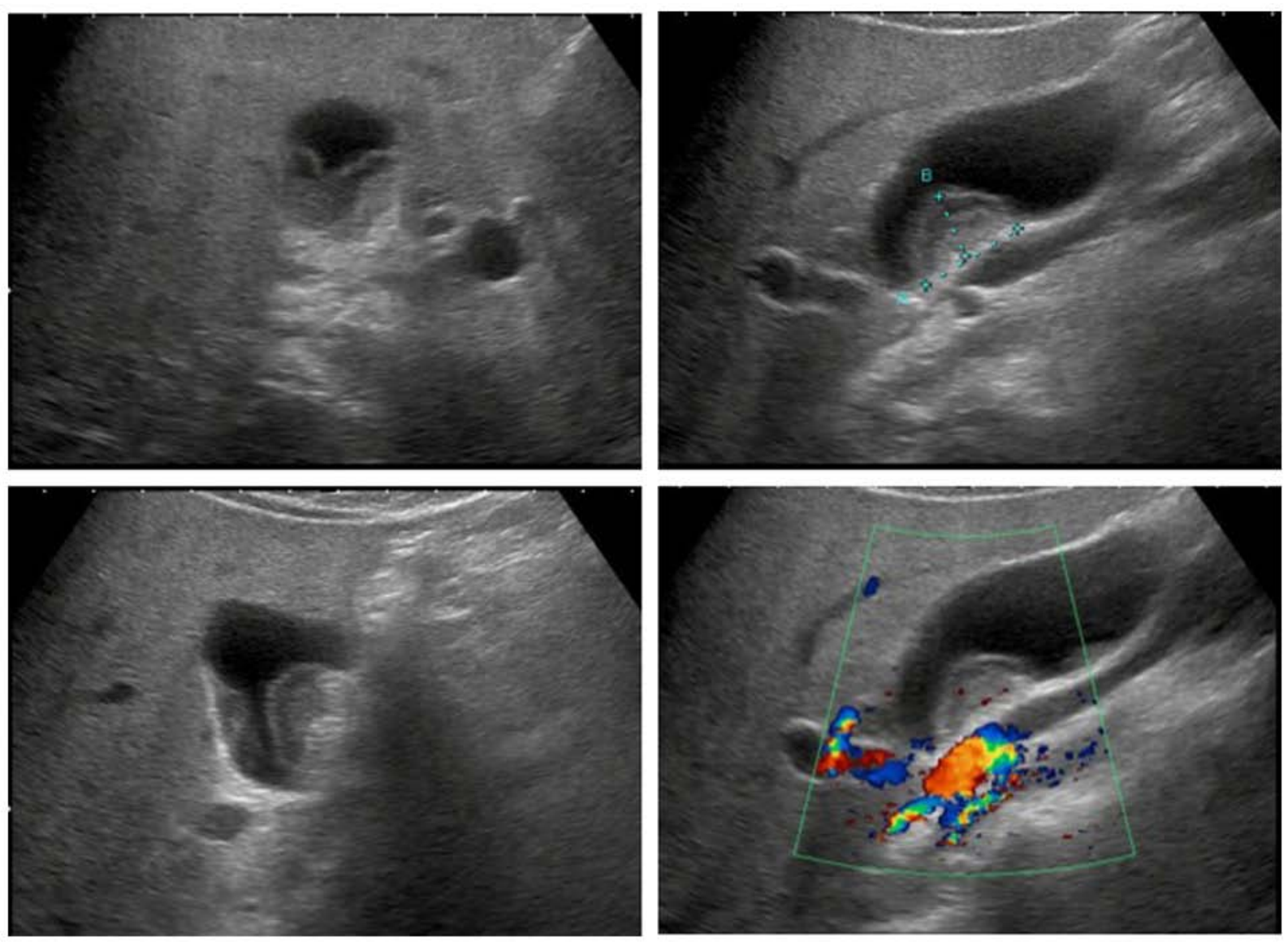

Figure 1. AUS showing thickened gallbladder wall and a structure of submucosal tumor-like appearance. Slight blood flow is detected on a Doppler ultrasound. AUS, abdominal ultrasonography.

A tumor $(45 \times 35 \mathrm{~mm})$ stretching from the body to the neck of the gallbladder was found in the resected specimen. Hematoxylin and eosin staining showed that the tumor cells had honeycomb growth with a high nucleus-to-cytoplasm ratio, submucosal growth in the shape of a cord, and numerous mitotic figures (20/10 high power fields; Fig. 6). In addition, Ki-67 labeling rate was $>80 \%$. The tumor cells were positive for synaptophysin, chromogranin A, and cluster of differentiation 56 (CD56). Immunohistochemical staining for somatostatin receptor (SSTR) 2A was negative. Based on these findings, the patient was diagnosed with gallbladder NEC. A small differentiated tubular adenocarcinoma was found on the mucosal surface; however, this made up only about $10 \%$ of the overall tumor, which does not meet the diagnostic criteria for mixed adenoneuroendocrine carcinoma (Fig. 7). The final pathological diagnosis was small cell NEC (pT3a, N, M0, stage II) Gbn, 45x35 mm, nodular-infiltrating type, circ, NEC, pT3a, int, INFb, ly1, v1, ne2, pCM0, pEM1, pR0. As multiple liver metastases were observed on CT 4 months after the operation, chemotherapy (CPT-11 [irinotecan] + cis-diamminedichloroplatinum [cisplatin]) was administered according to the regimen for small cell carcinoma of the lung. The patient is still undergoing treatment.

SSTR5 immunostaining was performed to elucidate why SRS was positive when SSTR2 immunostaining was negative, but we obtained a negative result. Additionally, we measured gene expression using quantitative real-time polymerase chain reaction (PCR) for all subtypes of SSTR (SSTR1-5) and compared our results with those of earlier studies that reported on the Caco2 cell line (3-5). The tumor was positive for all SSTR subtypes (Fig. 8) and may express SSTRs other than SSTR2 and SSTR5.

The study was approved by the ethics committee of Kagoshima University Hospital (approved number 26-6).

\section{Discussion}

Here, we report a rare case of gallbladder NEC preoperatively diagnosed using SRS. NETs occur in the gastrointestinal tract and bronchopulmonary system. Primary NEC of the gallbladder is a rare disease, accounting for only up to $1.4 \%$ of all gastrointestinal endocrine tumors and $0.4-4 \%$ of all malignant gallbladder tumors. In addition, the mean age of patients at disease onset is 64 years, and the incidence in females is relatively high (70\%). Gallbladder NEC is characterized by rapid development, early liver metastasis, lymph node metastasis, and direct metastasis, and the prognosis is considered to be extremely poor $(2,6,7)$. According to the 2010 World Health Organization classification of tumors of the digestive tract, NETs are categorized into NET G1, NET G2, and NECs according to mitotic count and Ki-67 index (8). NEC is difficult to preoperatively differentiate from gallbladder adenocarcinoma, and most patients are diagnosed postoperatively by immunostaining for markers such as NSE, CD56, 

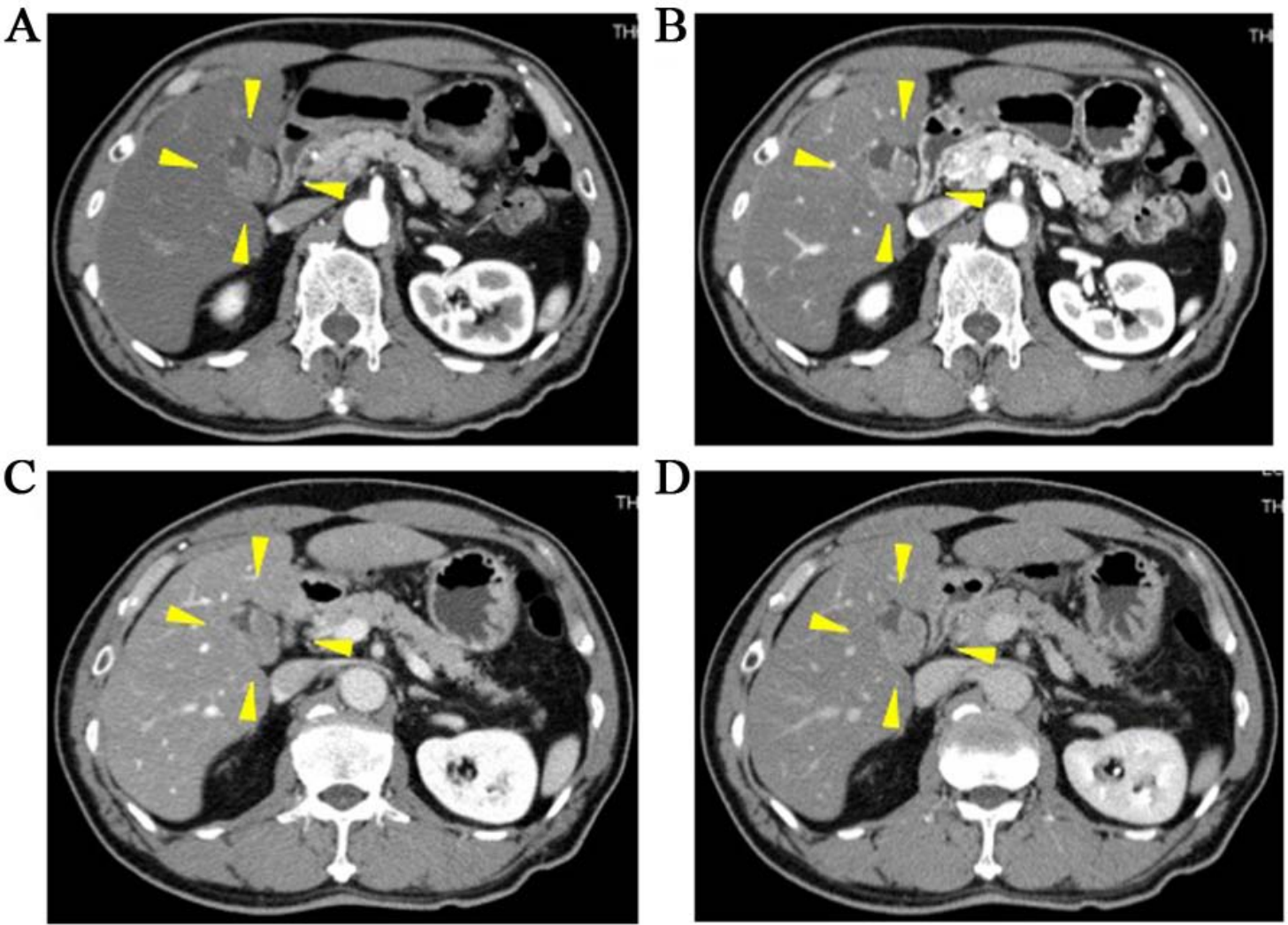

Figure 2. Abdominal contrast-enhanced computed tomography showing the thickened wall of the neck of the gallbladder and a slightly contrasted tumor. (A) Early arterial phase, (B) late arterial phase, (C) portal phase and (D) equilibrium phase. Yellow arrow, tumor site.

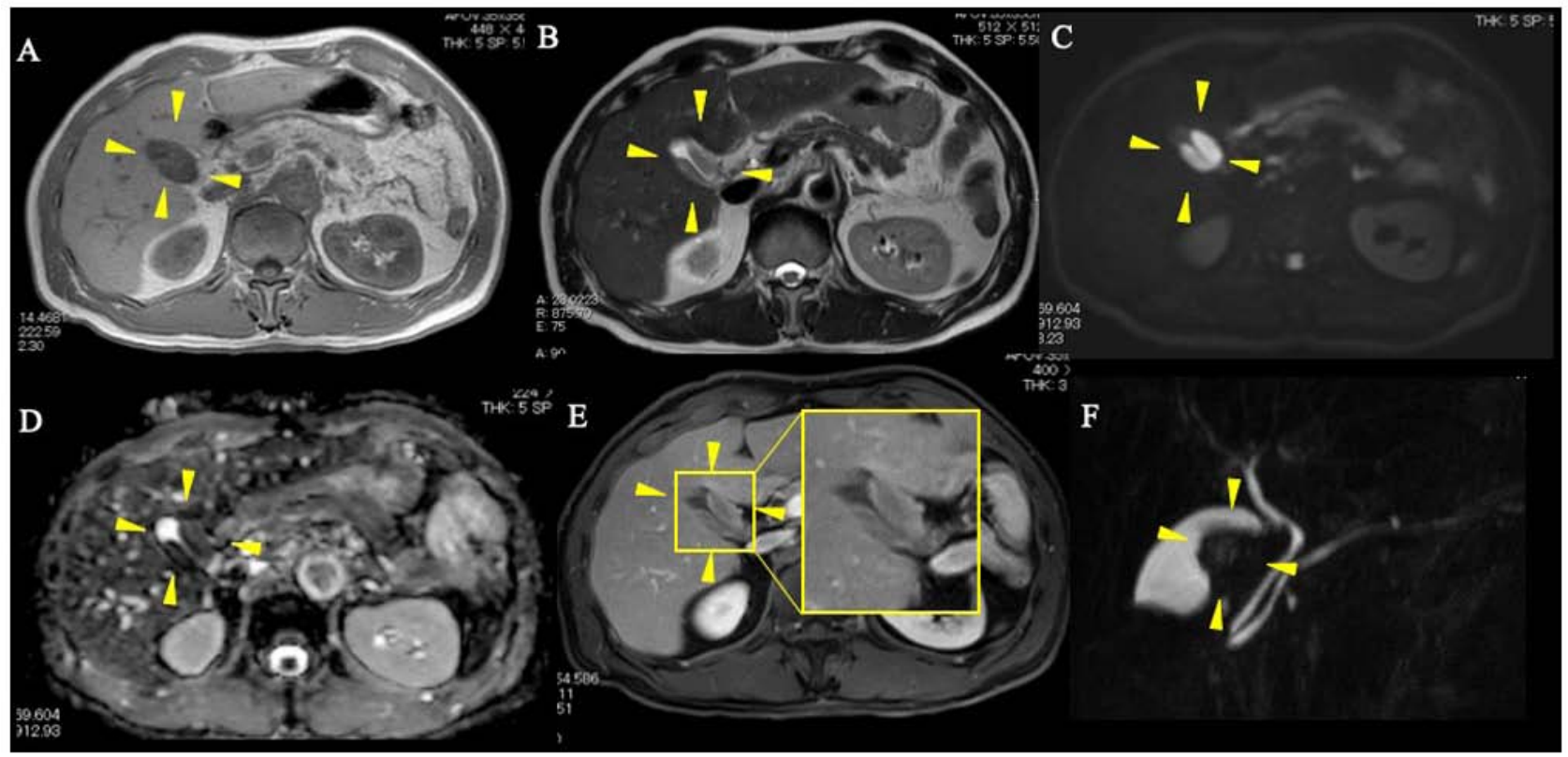

Figure 3. Abdominal gadolinium-ethoxybenzyl-enhanced MRI. (A) Tumor shows a low T1 signal (arrow), (B) a slightly high T2 signal (arrow), (C) an apparent high diffusion signal on diffusion-weighted imaging, (D) A signal that declined with apparent diffusion coefficient mapping, (E) ethoxybenzyl-enhanced MRI showing wall thickening that appear to extend into the lumen of the gallbladder and $(F)$ magnetic resonance cholangiopancreatography indicating a defect in the gallbladder neck. Yellow arrow, tumor site.

chromogranin A, and synaptophysin (9). Several hypotheses have been proposed on the pathogenesis of gallbladder NETs. A previous report posited that NETs are derived from undifferentiated pluripotent cells at the site of development, which are capable of differentiating into epithelial and neuroendocrine cells, and that this ability to differentiate changes during cancer proliferation and leads to a shift to small cell carcinoma (10). 

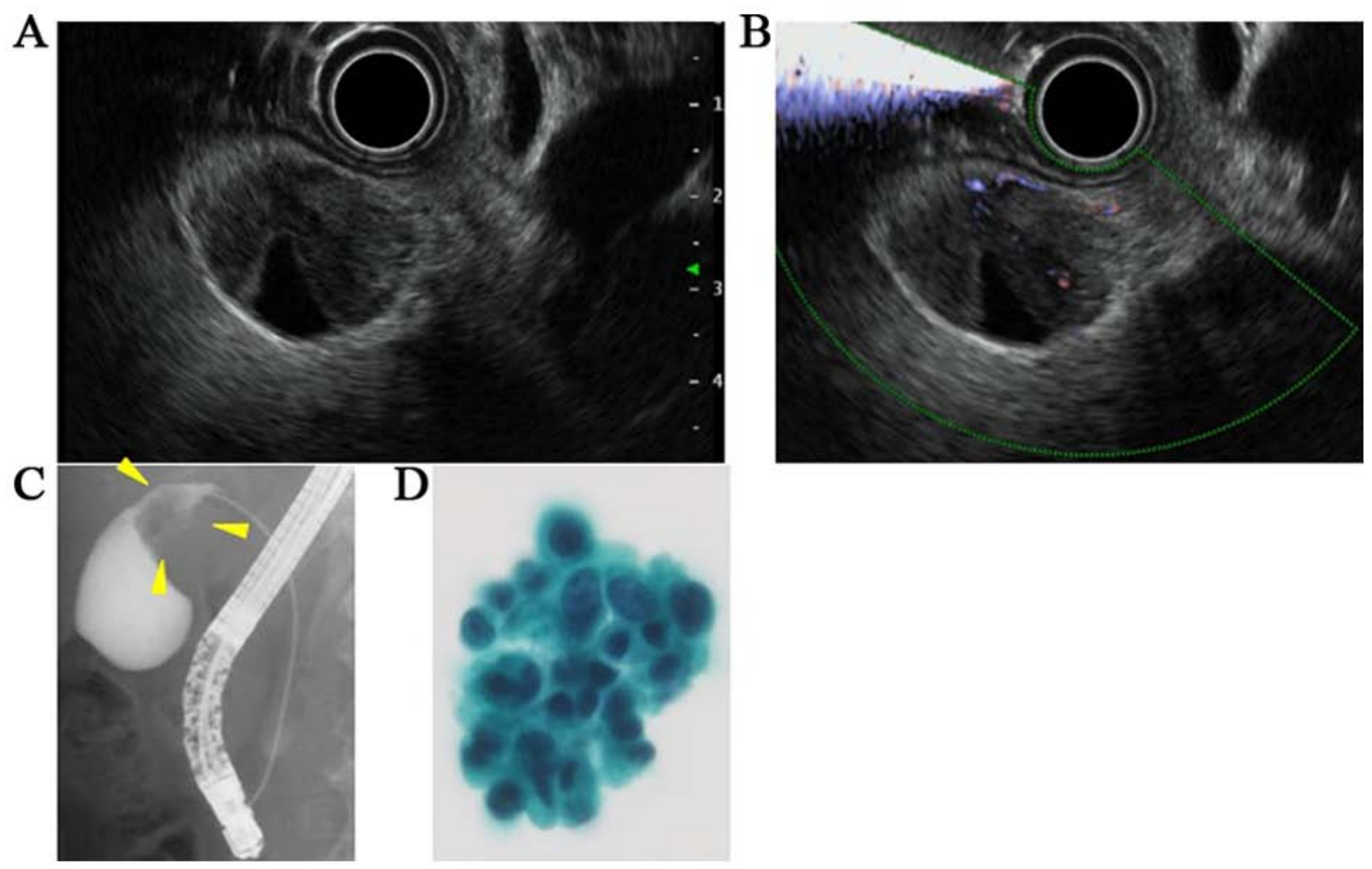

Figure 4. EUS showing a structure of submucosal tumor-like appearance with clear boundaries to the liver. (A) EUS B mode, (B) doppler mode, (C) ERCP showing a defect in the neck of the gallbladder (arrow) and (D) bile cytology. (A, B) No signs of Rokitansky-Aschoff sinus or calcification were indicated. The amylase level in the bile was not elevated (amylase; $397 \mathrm{U} / \mathrm{L}$ ). (D) An endoscopic naso-gallbladder drainage catheter is placed in the gall bladder and bile cytology is performed. The cytological diagnosis is suspected adenocarcinoma. EUS, Endoscopic ultrasonography; ERCP, endoscopic retrograde cholangiopancreatography.
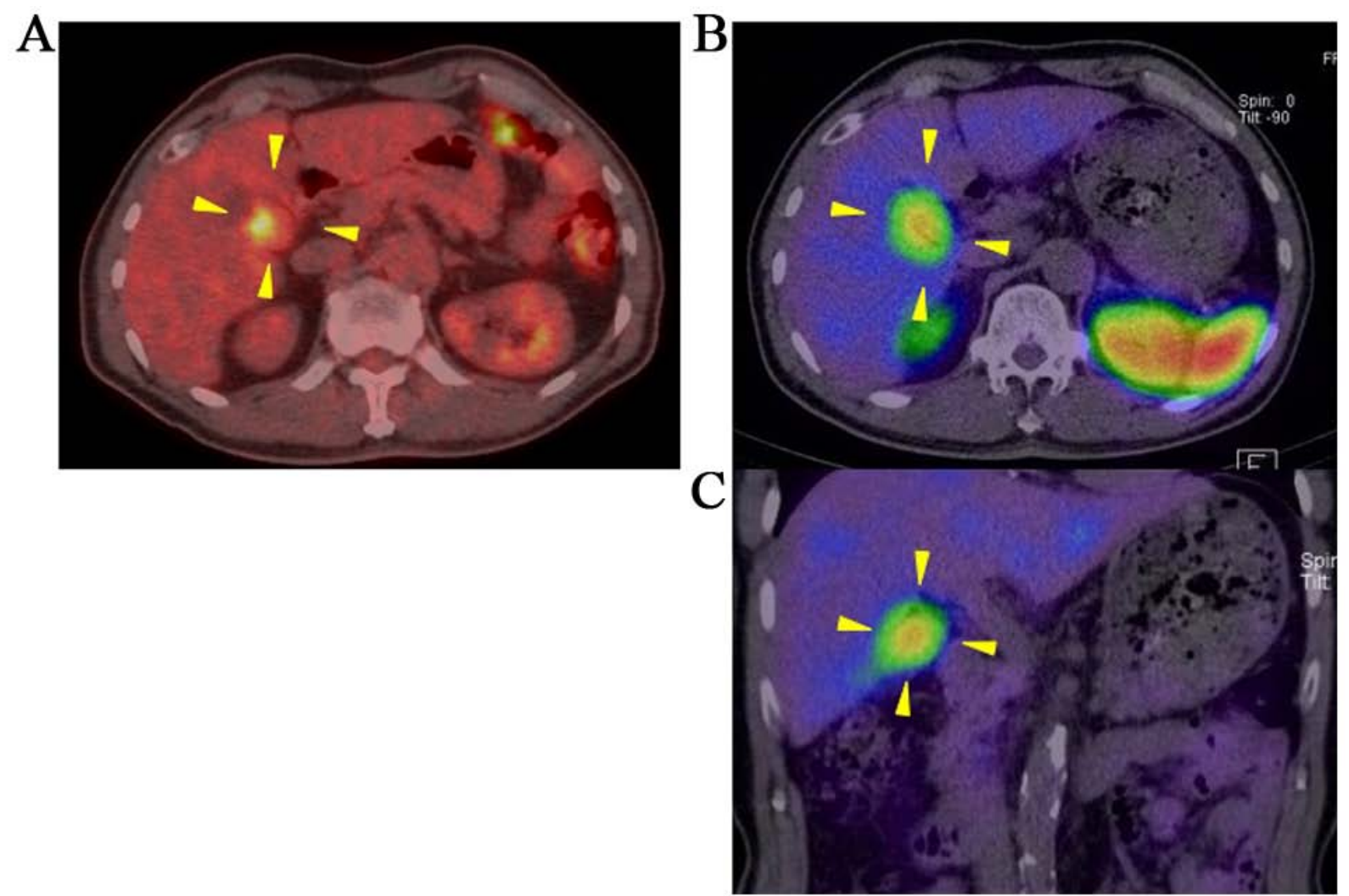

Figure 5. PET and SRS. (A) PET. SRS (B) horizontal image and (C) vertical axis image (arrow). Abnormal accumulation is apparent and is consistent with a tumor on PET and SRS. PET, positron emission tomography; SRS, somatostatin receptor scintigraphy. 

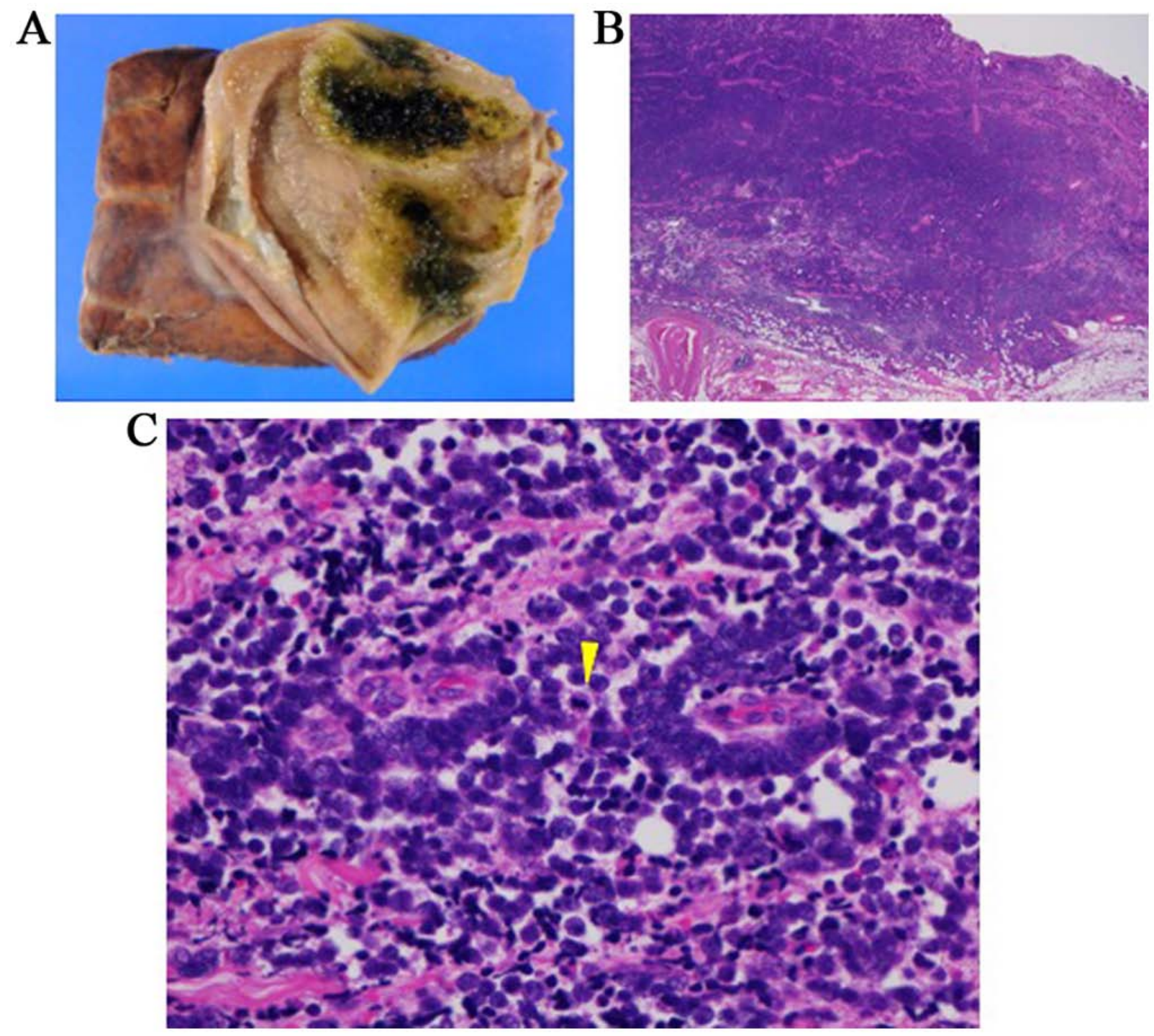

Figure 6. Pathological analysis. (A) Macroscopic features of the resected gallbladder. The tumor is a small cell neuroendocrine tumor (B) Hematoxylin and eosin staining (magnification, $\mathrm{x} 4$ ) and (C) nuclear fission (arrow; magnification $\mathrm{x} 400$ ).

No specific imaging features of gallbladder NECs have been described $(11,12)$. Many cases are difficult to distinguish from typical, more common gallbladder cancers. DWI in MRI has been reported to be useful for classifying NEC and adenocarcinoma components. As NECs have a higher proliferative potential than typical cancers and a high cell density, they have a relatively low diffusion ability (13). The gallbladder NEC in our patient had a high diffusion signal on DWI. DWI is considered potentially useful for differentiating between benign gallbladder tumors, typical gallbladder cancers, and gallbladder NECs (14).

SRS using ${ }^{111}$ In-pentetreotide, which targets somatostatin receptors (SSTRs) and has a high affinity for subtype 2A, is currently the gold standard functional imaging test for NETs (15). For the diagnosis of NETs, European and US guidelines recommend focal diagnosis using SRS, diagnosis of lymph node and liver metastases, and CT and MRI. The evaluation of SSTRs has also been reported to be useful for predicting therapeutic response to octreotide preparations (16). While SRS has a low diagnostic sensitivity for poorly differentiated NECs, FDG-PET is useful for the diagnosis of tumors with a high proliferation index. The diagnostic sensitivity is low for NETs with low proliferation index, slow growth rate, and low glucose consumption $(17,18)$. Although pathological examination revealed a poorly differentiated small cell NET in our patient, SRS and FDG-PET results were positive. In NETs, the lower the degree of differentiation, the lower the rate of SRS positivity and the higher the degree of PET accumulation. However, a comparative study reported that tumors with proliferation (Ki-67) indices $>15$ and $<2 \%$ had positive SRS sensitivities of 69 and $87 \%$, respectively. This suggests the possibility of SRS accumulation, even in NECs (17).

SSTRs, which are receptors of the peptide hormone somatostatin, have 5 subtypes, namely SSTR1, SSTR2, SSTR3, SSTR4, and SSTR5. ${ }^{111}$ In-pentetreotide has an affinity for SSTR2 and SSTR5. Generally, most NETs express SSTR2, and SRS is considered to be useful in the diagnosis of NETs (19). In NETs, the expression of SSTR2 decreases as the degree of differentiation decreases. In the case of our patient, immunohistochemical staining was negative for SSTR2A and SSTR5; however, real-time PCR detected the expressions of 

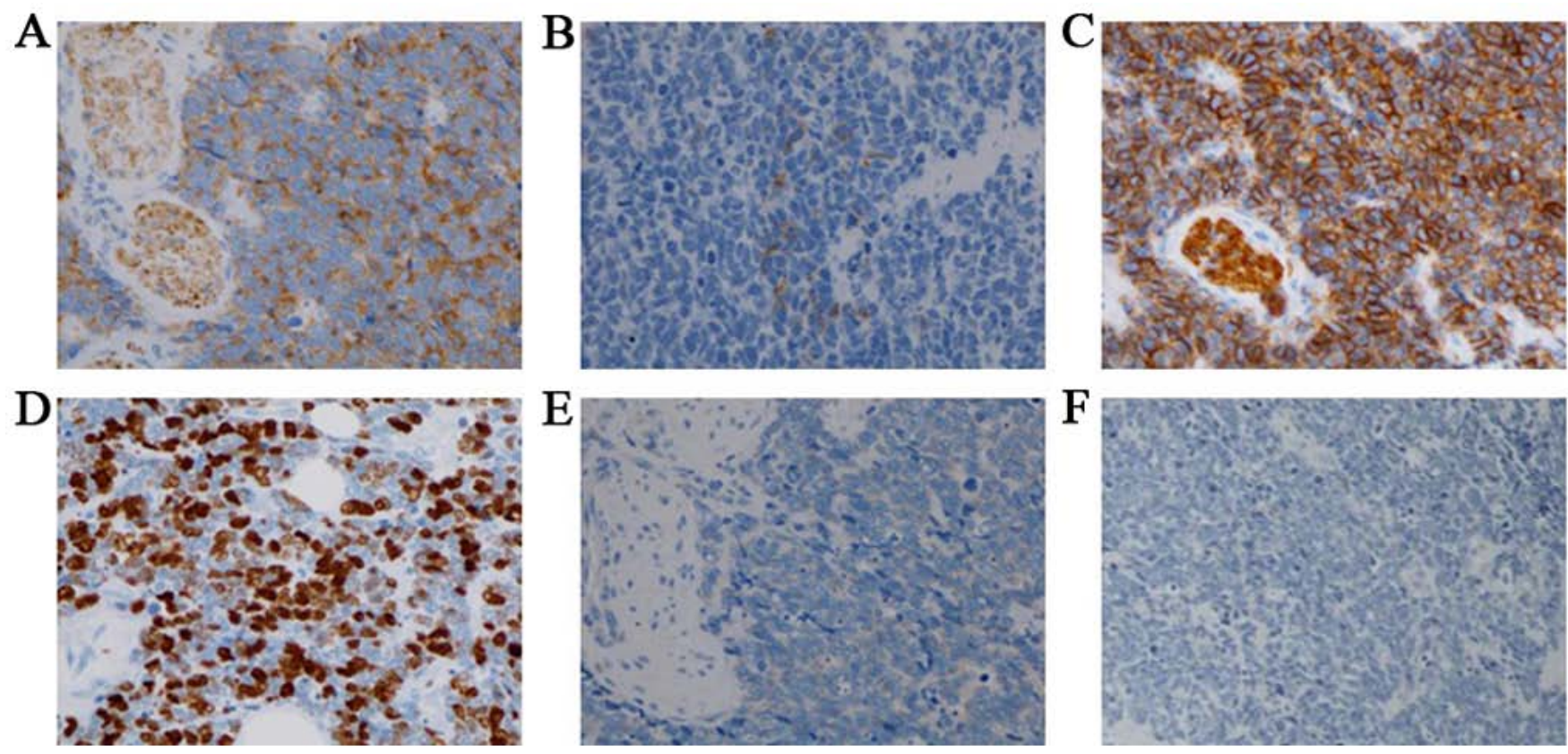

Figure 7. Immunohistochemical staining. (A) Synaptophysin, (B) Chromogranin A, (C) Cluster of differentiation 56 (CD56), (D) Ki-67, (E) SSTR2 and (F) SSTR5 The tumor cells in the gallbladder are positive for synaptophysin (A) chromogranin A (B) and CD56 (C) Over 80\% of the cells are positive for (D) Ki-67. The tumor cells are negative for (E) SSTR2 and (F) SSTR5 (F) All, magnification x40. CD56, cluster of differentiation 56; SSTR, somatostatin receptors.

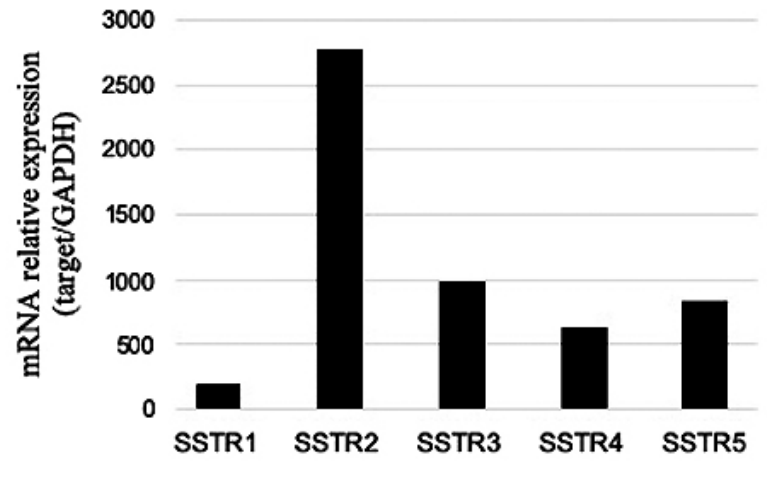

\begin{tabular}{|c|c|c|c|}
\hline Target & & Sequence & Products (bp) \\
\hline \multirow[t]{2}{*}{ SSTR 1} & forward & gagtcagctgtcggtcatc & 93 \\
\hline & reverse & ggaaagagcgcttgaagttg & \\
\hline \multirow[t]{2}{*}{ SSTR 2} & forward & dttgtggtggtcctcacct & 100 \\
\hline & reverse & gcagaggacattctggaagc & \\
\hline \multirow[t]{2}{*}{ SSTR 3} & forward & tcctctcctaccgcttcaa & 123 \\
\hline & reverse & atcctcctcatcctcctcet & \\
\hline \multirow[t]{2}{*}{ SSTR 4} & forward & tcttgtgctctgctggatg & 96 \\
\hline & reverse & ggataagggacacgtggttg & \\
\hline \multirow[t]{2}{*}{ SSTR 5} & forward & $\propto c t t c t t c a c c g t c a a c a t$ & 102 \\
\hline & reverse & gttggcgtaggagaggatga & \\
\hline \multirow[t]{2}{*}{ GAPDH } & forward & ggaaggtgaaggtcggagtca & 101 \\
\hline & reverse & gtcattgatggcaacaatatccact & \\
\hline
\end{tabular}

Figure 8. Reverse transcription-quantitative PCR for the measurement of the gene expression of all SSTR subtypes (SSTR1-5). SSTR, somatostatin receptors.

all the subtypes (SSTR1, SSTR2, SSTR3, SSTR4, and SSTR5; Fig. 8). SRS has a high affinity for SSTR2, SSTR5, and SSTR3. We postulated that the real-time PCR result, which suggested that, besides SSTR2 and SSTR5, the tumor may also express other SSTRs such as SSTR3, may explain the discrepancy between the loss of SSTR expression shown on immunohistochemistry and the apparent accumulation in the tumor shown on SRS. SRS may be useful for NEC diagnosis in some cases, even when immunohistochemical staining for SSTRs is negative.

Several limitations associated with the present study warrant mention. First, we performed immunohistochemical staining for SSTR2 and SSTR5 but not for SSTR1, SSTR3, and SSTR4, because we did not obtain antibodies against these subtypes. Second, we detected the expressions of SSTR1,
SSTR2, SSTR3, SSTR4, and SSTR5 using real-time PCR (Fig. 8) and compared our findings with those of earlier studies that reported on the Caco2 cell line $(4,5)$. Owing to the lack of tissue, we were not able to compare SSTR mRNA expression between the tumor and the adjacent normal tissue.

In conclusion, gallbladder NEC is a rare disease and is difficult to diagnose preoperatively. The incidence of this disease may increase in the future, and accurate diagnostic and effective treatment methods, which may include surgery and chemotherapy, must be established to improve prognosis. Gallbladder NET should be considered and SRS should be performed when evaluation of an advanced gallbladder tumor reveals normal levels of tumor markers, such as CEA and CA19-9, and atypical gallbladder tumor characteristics on imaging, such as apparent high diffusion signal on DWI. 


\section{Acknowledgements}

Not applicable.

\section{Funding}

No funding was received.

\section{Availability of data and materials}

The datasets used and/or analyzed during the present study are available from the corresponding author on reasonable request.

\section{Authors' contributions}

YK, drafted the manuscript. ST and AI, supervised and reviewed the contents of the manuscript and the data and image analysis. MK, HI, SA, FS, YN, SH, SK, MH and KG contributed to acquisition, analysis and interpretation of data, writing and revision of the manuscript critically for important intellectual content. All authors read and approved the final manuscript.

\section{Ethics approval and consent to participate}

The current study was approved by the ethics committee of Kagoshima University Hospital (approved no. 26-6).

\section{Patient consent for publication}

The consent for publication of the manuscript and the related images was obtained from the patients.

\section{Competing interests}

The authors declare that they have no competing interests.

\section{References}

1. Yao JC, Hassan M, Phan A, Dagohoy C, Leary C, Mares JE, Abdalla EK, Fleming JB, Vauthey JN, Rashid A and Evans DB: One hundred years after 'carcinoid': Epidemiology of and prognostic factors for neuroendocrine tumors in 35,825 cases in the United States. J Clin Oncol 26: 3063-3072, 2008.

2. Eltawil KM, Gustafsson BI, Kidd M and Modlin IM: Neuroendocrine tumors of the gallbladder: An evaluation and reassessment of management strategy. J Clin Gastroenterol 44: 687-695, 2010

3. Mizutani G, Nakanishi Y, Watanabe N, Honma T, Obana Y, Seki T, Ohni S and Nemoto N: Expression of somatostatin receptor (SSTR) subtypes (SSTR-1, 2A, 3, 4 and 5) in neuroendocrine tumors using real-time RT-PCR method and immunohistochemistry. Acta Histochem Cytochem 45: 167-176, 2012.

4. Ayiomamitis GD, Notas G, Zaravinos A, Drygiannakis I, Georgiadou M, Sfakianaki O, Mastrodimou N, Thermos K and Kouroumalis E: Effects of octreotide and insulin on colon cancer cellular proliferation and correlation with hTERT activity. Oncoscience 1: 457-467, 2014.
5. Colucci R, Blandizzi C, Ghisu N, Florio T and Del Tacca M: Somatostatin inhibits colon cancer cell growth through cyclooxygenase-2 downregulation. Br J Phasrmacol 155: 198-209, 2008.

6. Albores-Saavedra J, Batich K, Hossain S, Henson DE and Schwartz AM: Carcinoid tumors and small-cell carcinomas of the gallbladder and extrahepatic bile ducts: A comparative study based on 221 cases from the Surveillance, Epidemiology, and End Results Program. Ann Diagn Pathol 13: 378-383, 2009.

7. Yun SP, Shin N and Seo HI: Clinical outcomes of small cell neuroendocrine carcinoma and adenocarcinoma of the gallbladder. World J Gastroenterol 21: 269-275, 2015.

8. Hamilton SR and Aaltonen LA: World health organization classification of tumours. Pathology and genetics of tumours of the digestive system. Hamilton SR and Aaltonen LA (ed.) IARC Press, Lyon, pp2000, 2000.

9. Adachi T, Haraguchi M, Irie J, Yoshimoto T, Uehara R, Ito S, Tokai H, Noda K, Tada N and Hirabaru M: Gallbladder small cell carcinoma: A case report and literature review. Surg Case Rep 2: 71, 2016.

10. Horiguchi S: A case of neuroendocrine carcinoma of gallbladder. Tando 30: 290-297, 2016.

11. Chen C, Wang L, Liu X, Zhang G, Zhao Y and Geng Z: Gallbladder neuroendocrine carcinoma: Report of 10 cases and comparision of clinicopathologic features with gallbladder adenocarcinoma. Int J Clin Exp Pathol 8: 8218-8226, 2015.

12. El Fattach H, Guerrache Y, Eveno C, Pocard M, Kaci R, Shaar-Chneker C, Dautry R, Boudiaf M, Dohan A and Soyer P: Primary neuroendocrine tumors of the gallbladder: Ultrasonographic and MDCT features with pathologic correlation. Diagn Interv Imaging 96: 499-502, 2015.

13. Murawaki Y, Miura M, Otani Y and Yoshida M: A case of adenoendocrine cell carcinoma of the gallbladder complicated by pancreaticobiliary maljunction, whereby differences in tissue composition could be identified on diffusion-weighted MRI. Tando 27: 200-204, 2013.

14. Ogawa T, Horaguchi J, Fujita N, Noda Y, Kobayashi G, Ito K, Koshita S, Kanno Y, Masu K and Sugita R: High b-value diffusion-weighted magnetic resonance imaging for gallbladder lesions: Differentiation between benignity and malignancy. J Gastroenterol 47: 1352-1360, 2012.

15. O'Toole D, Kianmanesh R and Caplin M: ENETS 2016 consensus guidelines for the management of patients with digestive neuroendocrine tumors: An update. Neuroendocrinology 103: 117-118, 2016.

16. van Essen M, Sundin A, Krenning EP, and Kwekkeboom DJ: Neuroendocrine tumours: The role of imaging for diagnosis and therapy. Nat Rev Endocrinol 10: 102-114, 2014.

17. Binderup T, Knigge U, Loft A, Mortensen J, Pfeifer A, Federspiel B, Hansen CP, Højgaard L and Kjaer A: Functional imaging of neuroendocrine tumors: A head-to-head comparison of somatostatin receptor scintigraphy, 123I-MIBG Scintigraphy, and 18F-FDG PET. J Nucl Med 51: 704-712, 2010.

18. Kubota K, Okasaki M, Minamimoto R, Miyata Y, Morooka M, Nakajima $\mathrm{K}$ and Sato T: Lesion-based analysis of (18)F-FDG uptake and (111)In-Pentetreotide uptake by neuroendocrine tumors. Ann Nucl Med 28: 1004-1010, 2014.

19. Volante M, Brizzi MP, Faggiano A, La Rosa S, Rapa I, Ferrero A, Mansueto G, Righi L, Garancini S, Capella C, et al: Somatostatin receptor type $2 \mathrm{~A}$ immunohistochemistry in neuroendocrine tumors: A proposal of scoring system correlated with somatostatin receptor scintigraphy. Mod Pathol 20: 1172-1182, 2007.

This work is licensed under a Creative Commons Attribution-NonCommercial-NoDerivatives 4.0 International (CC BY-NC-ND 4.0) License. 